\title{
Association of Dry Eye Disease with Diabetic Retinopathy
}

\author{
Hina Nadeem¹, Tayyaba Gul Malik², Abdullah Mazhar ${ }^{2}$ and Aalia Ali ${ }^{1}$ \\ ${ }^{1}$ Department of Ophthalmology, Arif Memorial Teaching Hospital, Lahore, Pakistan \\ ${ }^{2}$ Department of Ophthalmology, Rashid Latif Medical College, Lahore, Pakistan
}

\begin{abstract}
Objective: To find out the relationship of dry eye disease with diabetic retinopathy, duration of diabetes and blood sugar levels in patients of type 2 diabetes using ocular surface disease index (OSDI).

Study Design: Cross sectional observational study.

Place and Duration of Study: Rashid Latif Medical College / Arif Memorial Teaching Hospital, Lahore, Pakistan, from January to June 2019.

Methodology: One hundred and thirty-six patients of type 2 diabetes, ages between 25 and 80 years of either gender, were selected from Outpatient Department of the Hospital. After clinical history, complete ocular examination including fundoscopy for diabetic retinopathy was performed. Random blood sugar levels were measured using Glucometer. OSDI was used to grade the dry eye disease (normal, mild, moderate and severe). Statistical analysis was done using SPSS version 25. ANOVA and Post-hoc Tukey test were used to find out the significance of the results.

Results: Among the 136 participants, 45 (33.10\%) were males and 91 (66.90\%) were females. Average age was $51.01 \pm 11.69$ years. Association of dry eye symptoms with increasing age and diabetic retinopathy was statistically significant $(p=0.031$ and $p=0.009$ respectively). Gender, duration of diabetes, tear meniscus height and blood sugar random (BSR) were not significantly related with dry eye symptoms ( $p=0.580,0.121,0.285$ and 0.536 , respectively).

Conclusion: Diabetic retinopathy and older age is significantly associated with dry eye disease. Diabetic patients who complain of dry eye should be referred to the ophthalmologists for fundoscopy to find out diabetic retinopathy.
\end{abstract}

Key Words: Dry eye disease, Ocular surface diseast index (OSDI), Diabetic retinopathy, Meibomian gland dysfunction, DEWS II.

How to cite this article: Nadeem H, Malik TG, Mazhar A, Ali A. Association of Dry Eye Disease with Diabetic Retinopathy. J Coll Physicians Surg Pak 2020; 30(05):493-497. DOI: https://doi.org/10.29271/jcpsp.2020.05.493.

\section{INTRODUCTION}

Ocular surface disease is not a single disorder rather it encompasses myriad conditions including dry eye disease (DED), blepharitis and meibomian gland dysfunction (MDG). Dry eye workshop study II (DEWS II) reporthas defined dry eye as: "a multifactorial disease of the ocular surface characterised by a loss of homeostasis of the tear film, and accompanied by ocular symptoms, in which tear film instability and hyperosmolarity, ocular surface inflammation and damage, and neurosensory abnormalities play etiological roles."1

The percentage of DED in diabetic patients varies. According to one study, it was $47.8 \%{ }^{2}$ Another study indicated tear film abnormality as a significant feature of diabetic ocular surface disease, which was due to poor quality and function of tears, combined with the subnormal ocular surface. ${ }^{3}$

Diagnosis of dry eye involves a series of tests including tear film breakup time (BUT), Schirmer test, tear meniscus, corneal staining and tear osmolarity.

Correspondence to: Dr. Tayyaba Gul Malik, Professor of Ophthalmology, Department of Ophthalmology, Rashid Latif

Medical College, Pakistan

E-mail: tayyabam@yahoo.com

Received: November 16, 2019; Revised: May 17, 2020;

Accepted: May 17, 2020

DOI: https://doi.org/10.29271/jcpsp.2020.05.493
Among many questionnaires for DED evaluation, OSDI is a standardised tool to evaluate symptoms without indulging in specialized tear film tests. ${ }^{4}$ Other questionnaires include: National eye institute visual function questionnaire-25, SPEED, CANDEES, DEEP, DEQ, IDEELOCI, SANDE and TERTC-DEQ. OSDI was introduced in 1997 by the Outcomes Research Group (Allergan Inc., Irvine, CA) and it is the most frequently used tool for DED in research. Alarge number of studies are available which have used this survey for DED. ${ }^{5,6}$

OSDI helps in identifying the disease at primary care setting, especially at physician level. One can simply give the questionnaire to the diabetic patients and identify those who need referral to the ophthalmologists. OSDI has also found its place in the studies, which investigate the efficacy of different treatment options for DED. ${ }^{7,8}$

We used OSDI in this particular study because it helps in finding out the dry eye earlier than the complications without undergoing sophisticated tests of dry eye. Another reason for using OSDI is that the Ophthalmologists pay major attention to the diabetic retinopathy and tear film instability is left unaddressed, unless the severity of the DED has brought the patient to the ophthalmologist's clinic with complications.

This study was conducted to find out a relationship of DED with diabetic retinopathy, duration of diabetes, BSR, gender, age and tearfilm heightusing OSDI. 
Table I: Relation of dry eye with study variables.

\begin{tabular}{|c|c|c|c|c|c|c|}
\hline \multirow[b]{2}{*}{ Study variable } & \multirow[b]{2}{*}{ Categories } & \multicolumn{4}{|c|}{ Dry eye disease } & \multirow[b]{2}{*}{ p-value } \\
\hline & & $\begin{array}{l}\text { Normal } \\
(n=16)\end{array}$ & $\begin{array}{c}\text { Mild } \\
(n=43)\end{array}$ & $\begin{array}{c}\text { Moderate } \\
n=55)\end{array}$ & $\begin{array}{l}\text { Severe } \\
(n=22)\end{array}$ & \\
\hline \multirow{2}{*}{ Gender } & Male & $5(31.30 \%)$ & $11(25.60 \%)$ & $20(36.40 \%)$ & $9(40.90 \%)$ & \multirow{2}{*}{0.580} \\
\hline & Female & $11(68.80 \%)$ & $32(74.40 \%)$ & $35(63.60 \%)$ & $13(59.10 \%)$ & \\
\hline \multirow{2}{*}{$\begin{array}{l}\text { Duration of } \\
\text { diabetes }\end{array}$} & $<5$ years & $10(62.50 \%)$ & $23(53.50 \%)$ & $21(38.20 \%)$ & $7(31.80 \%)$ & \multirow{2}{*}{0.121} \\
\hline & $>5$ years & $6(37.50 \%)$ & $20(46.50 \%)$ & $34(61.80 \%)$ & $15(68.20 \%)$ & \\
\hline \multirow{3}{*}{$\begin{array}{l}\text { Ocular } \\
\text { examination }\end{array}$} & Normal $(n=79)$ & $14(87.50 \%)$ & $29(67.40 \%)$ & $26(47.3 \%)$ & $10(45.50 \%)$ & \multirow{3}{*}{$0.036 . *$} \\
\hline & $\begin{array}{l}\text { Non-proliferative } \\
\text { diabetic retinopathy } \\
(n=42)\end{array}$ & $0(0.00 \%)$ & $11(25.60 \%)$ & $21(38.20 \%)$ & $10(45.50 \%)$ & \\
\hline & $\begin{array}{l}\text { Proliferative } \\
\text { diabetic retinopathy } \\
(n=14)\end{array}$ & $2(12.50 \%)$ & $3(7.00 \%)$ & $7(12.7 \%)$ & $2(9.10 \%)$ & \\
\hline \multirow{3}{*}{ Tear meniscus } & $<1 \mathrm{~mm}(\mathrm{n}=89)$ & $7(43.80 \%)$ & $29(67.40 \%)$ & $37(67.30 \%)$ & $16(72.70 \%)$ & \multirow{3}{*}{0.285} \\
\hline & $1 \mathrm{~mm}(\mathrm{n}=37)$ & $7(43.80 \%)$ & $11(25.60 \%)$ & $16(29.10 \%)$ & $3(13.60 \%)$ & \\
\hline & $>1 \mathrm{~mm}(\mathrm{n}=10)$ & $2(12.50 \%)$ & $3(7.00 \%)$ & $2(3.60 \%)$ & $3(13.60 \%)$ & \\
\hline
\end{tabular}

Table II: Relation of dry eye disease with age and BSR.

\begin{tabular}{|c|c|c|c|c|c|c|}
\hline & $\begin{array}{l}\text { Normal } \\
(n=16)\end{array}$ & $\begin{array}{l}\text { Mild dry eye } \\
\quad(n=43)\end{array}$ & $\begin{array}{l}\text { Moderate dry eye } \\
\qquad(n=55)\end{array}$ & $\begin{array}{l}\text { Severe dry eye } \\
(n=22)\end{array}$ & $\begin{array}{c}\text { Total } \\
(n=136)\end{array}$ & p-value \\
\hline AGE & $45.31 \pm 13.27$ & $49.77 \pm 11.32$ & $51.58 \pm 12.24$ & $56.18 \pm 7.35$ & $51.01 \pm 11.69$ & $0.031^{*}$ \\
\hline BSR & $184.06 \pm 68.46$ & $217.40 \pm 113.08$ & $225.71 \pm 103.64$ & $213.36 \pm 76.31$ & $216.18 \pm 99.31$ & 0.536 \\
\hline
\end{tabular}

Table III: Post Hoc Tukey's test (*the mean difference is significant at the $\mathbf{0 . 0 5}$ level).

\begin{tabular}{|c|c|c|c|c|c|}
\hline Dependent variable & $\begin{array}{c}\text { (I) } \\
\text { Dry eye }\end{array}$ & $\begin{array}{c}\text { (J) } \\
\text { Dry eye }\end{array}$ & $\begin{array}{c}(I-J) \\
\text { Mean difference }\end{array}$ & Sig. & $\begin{array}{c}95 \% \\
\text { Confidence Interval }\end{array}$ \\
\hline \multirow{12}{*}{ Age } & \multirow{3}{*}{ Normal } & Mild & -4.455 & 0.545 & $-13.16-4.25$ \\
\hline & & Moderate & -6.269 & 0.22 & $-14.72-2.18$ \\
\hline & & Severe & $-10.869 *$ & 0.023 & $-20.64--1.1$ \\
\hline & \multirow{3}{*}{ Mild } & Normal & 4.455 & 0.545 & $-4.25-13.16$ \\
\hline & & Moderate & -1.814 & 0.863 & $-7.87-4.24$ \\
\hline & & Severe & -6.414 & 0.146 & $-14 .^{`} 21-1.38$ \\
\hline & \multirow{3}{*}{ Moderate } & Normal & 6.269 & 0.22 & $-2.18-14.72$ \\
\hline & & Mild & 1.814 & 0.863 & $-4.24-7.87$ \\
\hline & & Severe & -4.6 & 0.385 & $-12.1-2.9$ \\
\hline & \multirow{3}{*}{ Severe } & Normal & 10.869* & 0.023 & $1.1-20.64$ \\
\hline & & Mild & 6.414 & 0.146 & $-1.38-14.21$ \\
\hline & & Moderate & 4.6 & 0.385 & $-2.9-12.1$ \\
\hline \multirow{12}{*}{ BSR } & \multirow{3}{*}{ Normal } & Mild & -33.33 & 0.664 & $-109.23-42.57$ \\
\hline & & Moderate & -41.65 & 0.457 & $-115.27-31.97$ \\
\hline & & Severe & -29.3 & 0.807 & $-114.46-55.86$ \\
\hline & \multirow{3}{*}{ Mild } & Normal & 33.333 & 0.664 & $-42.57-109.23$ \\
\hline & & Moderate & -8.314 & 0.977 & $-61.07-44.45$ \\
\hline & & Severe & 4.032 & 0.999 & $-63.91-71.97$ \\
\hline & \multirow{3}{*}{ Moderate } & Normal & 41.647 & 0.457 & $-31.97-115.27$ \\
\hline & & Mild & 8.314 & 0.977 & $-44.45-61.07$ \\
\hline & & Severe & 12.345 & 0.961 & $-53.04-77.73$ \\
\hline & \multirow{3}{*}{ Severe } & Normal & 29.301 & 0.807 & $-55.86-114.46$ \\
\hline & & Mild & -4.032 & 0.999 & $-71.97-63.91$ \\
\hline & & Moderate & -12.35 & 0.961 & $-77.73-53.04$ \\
\hline
\end{tabular}




\section{METHODOLOGY}

It was a cross-sectional observational study carried out in hospital from January to June 2019. Institutional Ethical Review Board approved the study. Sample size was calculated by WHO software 2.0 using the following formula: $Z^{2}{ }_{1-\alpha / 2}(p)$ $(1-p) / d^{2}$.

One hundred and thirty-six patients were selected by non-probability convenient sampling from Outpatient Department of Arif Memorial Teaching Hospital. Patients of type 2 diabetes between 25 and 80 years of age of either genders were included in the study. Exclusion criteria were: patients with systemic diseases other than diabetes, type 1 diabetic patients, smokers, patients who had undergone any treatment for diabetic retinopathy, patients with vitreo-retinal diseases other than diabetic retinopathy, using any medicine which can cause dry eye (antidepressants, anxiolytics, antihistamines, anticholinergics, anti-hypertensive, antipsychotics, antiparkinsonians and diuretics), any evidence of Vitamin A deficiency (Bitot's spot, night blindness), use of topical medications, history of wearing contact lenses and previous Kerato-refractive/cataract surgery.

Informed consent was taken from every patient. After clinical history, examination was performed. Random blood sugar levels were measured using Glucometer. Visual acuity was checked for distance and proximity. Pupillary reactions were checked. Slit lamp examination was performed to inspect any anterior segment abnormality. Goldman tonometry was done to check intra-ocular pressures. Fundus examination was performed using 90-D lens at slit lamp and with indirect ophthalmoscope. Retinal findings were categorized into, NAD (no abnormality detected), NPDR (non-proliferative diabetic retinopathy) and PDR (proliferative diabetic retinopathy). OSDI was used to categorize the dry eye symptoms into no symptoms, mild, moderate and severe.

Categorical data like gender, duration of diabetes, ocular examination and tear meniscus were presented in the form of frequency and percentages and continuous variables like age and BSR were presented in the form of mean \pm standard deviation. Statistical analysis was done using SPSS version 25. ANOVA followed by Post-hoc Tukey's test were used to find out the significance differences of means. Association of categorical data was assessed using chi square. Significance was set at $<0.05$ with $95 \%$ confidence interval.

\section{RESULTS}

Among 136 participants, 45 (33.10\%) were males and 91 $(66.90 \%)$ were females. Average age was $51.01 \pm 11.69$ years. Sixty-one $(44.90 \%)$ patients had diabetes for less than five years and $75(55.2 \%)$ patients for longer. On fundoscopic examination, 79 (58.50\%) patients did not have diabetic retinopathy, 42 (31.10\%) had NPDR and 14 (10.30\%) had PDR. Tear meniscus height was $<1 \mathrm{~mm}$ in $89(65.40 \%)$ patients, $1 \mathrm{~mm}$ in $37(27.20 \%)$ and $>1 \mathrm{~mm}$ in $10(7.40 \%)$ patients. Association of dry-eye symptoms with increasing age was statistically significant $(p=0.031)$. Gender $(p=0.580)$, duration of Diabetes $(p=0.121)$, tear meniscus height $(p=0.285)$ and BSR $(p=0.536)$ were not significantly related with dry eye disease. However, diabetic retinopathy was significantly related with dry eye $(p=0.036)$ (Table I, II, III).

\section{DISCUSSION}

OSDI is a 12-item questionnaire, which investigates dry eye symptomatically and assess the vision related problems associated with dry eye in the previous week of patient. OSDI includes three categories of questions; ocular symptoms, vision-related problems and environmental factors. ${ }^{9}$ OSDI is a multi-dimensional questionnaire and it focuses on the quality of vision and quality of life. When comparison was done between patients with DED and normal subjects, it had good specificity (0.83) and a moderate sensitivity $(0.60) .{ }^{10}$ When OSDI and TBUT results were compared, it revealed a significant inverse relationship between OSDI and TBUT. ${ }^{11}$

According to a clinical research, $73.6 \%$ of type 2 diabetic patients suffer from complications of dry eye including punctate keratopathy, endothelial dystrophy, and recurrent erosions in some part of their life. ${ }^{12}$ Hence, it is the responsibility of the treating physicians as well as ophthalmologists to prevent these complications. Relation of duration of diabetes with DED shows varying results. If we find the relation of severity of DED with duration of diabetes, it indicates that longer the duration of diabetes, severe is the DED. ${ }^{13}$ As the duration of disease increases, patients become asymptomatic because of reduced corneal sensitivity attributed to diabetic peripheral neuropathy. This leads to increased disease severity but the symptoms become less appreciable which are addressed in the OSDI score. However, with increasing duration of diabetes, patients are often asymptomatic even in the presence of serious ocular surface damage due to reduced corneal sensitivity, which reflects the progression of diabetic peripheral neuropathy. ${ }^{12}$ Similarly, there are other studies, which show that shorter duration of diabetes was associated with high OSDI scores and patients with longstanding diabetes had fewer symptoms. ${ }^{14}$ This could be the reason that in this particular study we did not find any significant relationship of duration of diabetes with dry eye symptoms. Decreased corneal sensitivity leads to lesser awareness of dry eye. Blinking is also decreased due to reduced corneal sensitivity resulting in increased evaporation and severity of disease. Another reason for lower OSDI scores in longer duration of diabetes could be decreased basal and reflex tearing. This increases tear osmolarity which might be responsible for low OSDI scores. Disparity between the clinical signs and symptoms of DED was also described by DeMill et al. ${ }^{12}$

In this study, statistically significant association of dry eye symptoms was found with increasing age. Recent reports by Khetwani et al. who used OSDI, also showed relation of age with DED in diabetic patients. ${ }^{15}$

No significant association of high blood sugar level was found with DED $(p=0.536)$ in our patients. This is in contradiction to a community-based Chinese study in which there was a significant association between the presence of DED and higher blood glucose ( $p<0.001$, OR1.240) as well as higher levels of glycosylated hemoglobin $\mathrm{HbAlc}\left(p<0.001\right.$, OR1.108). ${ }^{16}$ 
The present results showed that diabetic retinopathy was significantly related with dry eye $(p=0.036)$. An Egyptian study also found highly statistically significant relation between severity of dry eye and diabetic retinopathy. ${ }^{17}$ Similarly, another group of researchers found that DED was seen more frequently with PDR. There was a significant correlation between $D E D$ and retinopathy $(\mathrm{OR}=2.29, \mathrm{Cl}=1.16-4.52$, $\mathrm{p}=0.016){ }^{18}$

International Dry Eye Workshop 2017 classified diabetes as a risk factor for aqueous-deficient dry eye. ${ }^{19}$ There are multiple factors, which contribute to DED in diabetic patients. Microvascular changes caused by hyperglycemia is one of these factors. Hyperglycemia leads to microvascular damage to the lacrimal glands resulting in decreased tear production. Diabetic neuropathy also plays multiple roles in producing DED in diabetic patients. These include; decreased lacrimal gland innervation resulting in decreased tear production. ${ }^{20}$ Reduced reflex tearing caused by decreased corneal sensitivity is another factor and decreased corneal sensitivity resulting in reduced mucin secretion by the goblet cells. MGD is also related with dry eye symptoms in diabetic patients. ${ }^{21}$ Recently, role of substance $P$ in maintaining the corneal integrity was also recognized. Decreased substance $P$ in tears of diabetic patients impairs corneal epithelial homeostasis leading to progression of dry eye symptoms. ${ }^{22}$ Effect of insulin on meibomian gland cells was also identified as a factor to DED indicating role of insulin in maintaining the integrity of meibomian gland epithelial cells. ${ }^{23}$

Strength of this particular study is that a simplified questionnaire was used for an early diagnosis of DED, which can help prevent complications and improve quality of life.

Limitation of this study is that OSDI does not take into account other symptoms of the patients, rather it is limited to the particular questions of the questionnaire. Type 1 diabetes was also not considered, which may show different results. HbAlC was not evaluated, which is a better indicator of control of diabetes.

As OSDI is a useful tool for DED evaluation, it should be used by diabetologists as a routine screening instrument for DED in diabetic patients. A dry eye examination should be added to the routine screening of diabetes.

\section{CONCLUSION}

Severity of diabetic retinopathy is significantly related with dry eye disease. Patients with diabetic retinopathy should be examined for dry eye; and diabetic patients, who complain of dry eye, should be referred to the ophthalmologists for fundoscopy to find out diabetic retinopathy.

\section{ETHICAL APPROVAL:}

The institutional review board approved the research.

\section{PATIENTS' CONSENT:}

Informed consent was taken from every patient.

\section{CONFLICT OF INTEREST:}

Authors declare no conflict of interest in this study.

\section{AUTHORS' CONTRIBUTION:}

HN: Data acquisition, data analysis, final manuscript review. TGM: Research planning, data acquisition and analysis, literature research, manuscript writing and final review.

AM: Data acquisition and analysis, literature research, manuscript writing and final review.

AA: Data acquisition and analysis, literature research and final review.

\section{REFERENCES}

1. Craig JP, Nelson JD, Azar DT, Belmonte C, Bron AJ, Chauhan SK, et al. TFOS DEWS II Report Executive Summary. Ocul Surf 2017; 15:802-12.

2. Devi RS, Gowda MS. Dry Eye in Diabetes Mellitus Patients and its Relationship with Diabetic Retinopathy. IJSS 2016; 4:67-72.

3. Kesarwani D, Rizvi SWA, Khan AA, Amitava AK, Vasenwala SM, Siddiqui Z. Tear film and ocular surface dysfunction in diabetes mellitus in an Indian population. Indian J Ophthalmol 2017; 65:301-4.

4. Ozcura F, Aydin S, Helvaci MR. Ocular surface disease index for the diagnosis of dry eye syndrome. Ocul Immunol Inflamm 2007; 15:389-93.

5. Gurdal C, Sarac O, Genc I, Kirimlioglu H, Takmaz T, Can I. Ocular surface and dry eye in Graves' disease. Curr Eye Res 2011; 36:8-13.

6. Rossi GC, Tinelli C, Pasinetti GM, Milano G, Bianchi PE. Dry eye syndrome-related quality of life in glaucoma patients. Eur J Ophthalmol 2009; 19:572-579.

7. Monaco G, Cacioppo V, Consonni D, Troiano P. Effects of osmoprotection on symptoms, ocular surface damage, and tear film modifications caused by glaucoma therapy. Eur J Ophthalmol 2011; 21:243-50.

8. Luchs JI, Nelinson DS, Macy JI. Efficacy of hydroxypropyl cellulose ophthalmic inserts (LACRISERT) in subsets of patients with dry eye syndrome: findings from a patient registry. Cornea 2010; 29:1417-27.

9. Grubbs JR, Tolleson-Rinehart S, Huynh K, Davis RM. A review of quality of life measures in dry eye questionnaires. Cornea 2014; 33:215-218.

10. Schiffman RM, Christianson RM, Christianson MD, Jacobsen G, Hirsch JD, Reis BL. Reliability and validity of the Ocular Surface Disease Index. Arch Ophthalmol 2000; 118:615-21.

11. Özcura F, Aydin S, Helvaci MR. Ocular surface disease index for the diagnosis of dry eye syndrome. Ocul Immunol Inflamm 2007; 15:389-93.

12. DeMill DL, Hussain M, Pop-Busui R, Shtein RM. Ocular surface disease in patients with diabetic peripheral neuropathy. $\mathrm{Br} J$ Ophthalmol 2016; 100:924-8.

13. Fanglin HE, Zhao Z, Liu Y, Lu L, Fu Y. Assessment of ocular surface damage during the course of type 2 diabetes mellitus. J Ophthalmol 2018;1206808:8.

14. Fuerst N, Langelier N, Massaro-Giordano M, Pistilli M, Stasi K, Burns C, Cardillo S, Bunya VY. Tear osmolarity and dry eye symptoms in diabetics. Clin Ophthalmol 2014; 8:507-15.

15. Khetwani D, Karambelkar VH, Gadre GA. Ocular surface disorders in type 2 diabetes mellitus. Int J Contemp Med Res 2019; 6:98.46.

16. Zou X, Lu L, Xu Y, Zhu J, He J, Zhang B, Zou H. Prevalence and clinical characteristics of dry eye disease in community-based type 2 diabetic patients: the Beixinjing eye study. BMC 
Ophthalmology 2018; 117:18.

17. Kamel SS, Mohammed TH, El Zankalony YA, Saad AH. Prevalence of dry eye in diabetics. J Egypt Ophthalmol Soc 2017; 110:77-82.

18. Najafi $P$, Malek $M$, Valojerdi $A E$, Aghili $R$, Khamseh ME, Fallah $A E$, Tokhmehchi MRF, Behrouz MJ. Dry eye and its correlation to diabetes microvascular complications in people with type 2 diabetes mellitus. J Diabetes Complications 2013; 27:459-62.

19. Bron AJ, De PCS, Chauhan SK, Bonini S, Gabison EE, Jain S, Knopet $E$, et al. The ocular surface TFOS DEWS II pathophysiology report," Ocular Surface, 2017; 15:438-510.

20. Lv H, Li A, Zhang X, Xu M, Qiao Y, Zhang J, Yu L. Meta-analysis and review on the changes of tear function and corneal sensitivity in diabetic patients. Acta Ophthalmol 2014; 92:e96e104.

21. Misra SL, Patel DV, McGhee CNJ, Pradhan M, Kilfoyle D, Braatvedt $\mathrm{GD}$, et al. Peripheral neuropathy and tear film dysfunction in type 1 diabetes mellitus. J Diabetes Res 2014; 2014:848659.

22. Markoulli M, You J, Kim J, Duong CL, Tolentino JB, Karras J, Lum E. Corneal nerve morphology and tear film substance $\mathrm{P}$ in diabetes. Optom Vis Sci 2017; 94:726-31.

23. Ding J, Liu Y, Sullivan DA. Effects of insulin and high glucose on human meibomian gland epithelial cells. Invest Ophthalmol Vis Sci 2015; 56:7814-20. 